\section{Timing and Duration of Supplemental Lighting during the Seedling Stage Influence Quality and Flowering in Petunia and Pansy}

\author{
Wook Oh${ }^{1}$, Erik S. Runkle ${ }^{2}$, and Ryan M. Warner \\ Department of Horticulture, Michigan State University, A288 Plant and Soil \\ Sciences Building, East Lansing, MI 48824
}

Additional index words. assimilation lighting, daily light integral, plant growth, Viola

\begin{abstract}
Increasing the photosynthetic daily light integral (DLI) during the seedling stage promotes seedling growth and flowering in many bedding plants. Our objective was to determine the impact of increased DLI for different periods during the seedling stage on young plant quality and subsequent growth and development. Seeds of petunia (Petunia $\times$ hybrida Vilm.-Andr. 'Madness Red') and pansy (Viola $\times$ wittrockiana Gams. 'Delta Premium Yellow') were sown into 288-cell plug trays and placed under a 16-h photoperiod provided by sunlight plus $90 \mu \mathrm{mol} \cdot \mathrm{m}^{-2} \cdot \mathrm{s}^{-1}$ [supplemental lighting (SL)] or $3 \mu \mathrm{mol} \cdot \mathrm{m}^{-2} \cdot \mathrm{s}^{-1}$ [photoperiodic lighting (PL)] from high-pressure sodium lamps when the ambient greenhouse photosynthetic photon flux was less than $400 \mu \mathrm{mol} \cdot \mathrm{m}^{-2} \cdot \mathrm{s}^{-1}$ from 0600 to $2200 \mathrm{HR}$. Plants were grown at $20^{\circ} \mathrm{C}$ under PL or SL for the entire seedling stage or were exposed to $\mathrm{SL}$ for one-third or two-thirds of the seedling stage. Seedlings were then transplanted into $10-\mathrm{cm}$ pots and grown until flowering with SL at $20^{\circ} \mathrm{C}$. Shoot dry mass of transplants increased linearly with increasing DLI provided to seedlings in petunia $\left(y=-4.75+1.86 x, R^{2}=0.76\right)$ and pansy $\left(y=-3.94+3.47 x, R^{2}=0.78\right)$ in which $y=$ dry mass (g) and $x=$ DLI $\left(\mathrm{mol} \cdot \mathrm{m}^{-2} \cdot \mathrm{d}^{-1}\right)$. SL during the last two-thirds or the entire plug stage increased shoot dry mass and the number of leaves in both species compared with SL during the earlier stage or PL. SL during the last two-thirds or the entire plug stage accelerated flowering, but plants had a lower shoot dry mass and flower bud number at first flowering compared with that in SL during the first third or two-thirds or that in PL. Therefore, SL generally had greater effects on transplant quality and subsequent flowering when provided later in the plug stage than if provided earlier in production.
\end{abstract}

The majority of herbaceous ornamental plants are commercially produced in greenhouses so that they are in flower when marketed to consumers in the spring. Most garden plants are produced in two distinct phases: a young plant stage, in which seedlings and cuttings are established, and a finish plant stage, in which the young plants are transplanted into a larger container and grown until marketable (Ball, 1998). During the young plant stage, seedling plugs are typically produced during the winter and early

Received for publication 17 Mar. 2010. Accepted for publication 8 July 2010.

This work was supported by the Korea Research Foundation Grant funded by the Korean Government (MOEHRD) (KRF-2007-357-F00008), greenhouse growers providing support for Michigan State University floriculture research, and the Michigan Agricultural Experiment Station

We thank Mike Olrich and student employees for their greenhouse assistance and Sang-Wook Hong, Sungji Publishing Co. Inc., Korea, for financial support.

${ }^{1}$ Former postdoctoral research associate. Currently assistant professor, Department of Horticulture, Yeungnam University, Gyeongsan, Gyeongbuk 712-749, Republic of Korea.

${ }^{2}$ To whom reprint requests should be addressed; e-mail runkleer@msu.edu. petunia (Petunia $\times$ hybrida Vilm.-Andr.; Kaczperski et al., 1991), and eight other bedding plants (Faust et al., 2005). Vinca grown under the average DLI of 18 $\mathrm{mol} \cdot \mathrm{m}^{-2} \cdot \mathrm{d}^{-1}$ had a flower diameter of $3.9 \mathrm{~cm}$ compared with $3.3 \mathrm{~cm}$ for plants grown under $9 \mathrm{~mol} \cdot \mathrm{m}^{-2} \cdot \mathrm{d}^{-1}$. Chrysanthemum flower bud number increased from 3.0 to 10.2 as DLI increased from 9.8 to $16.9 \mathrm{~mol} \cdot \mathrm{m}^{-2} \cdot \mathrm{d}^{-1}$ under an 8-h photoperiod (Warrington and Norton, 1991). Petunia grown under a higher DLI had more and larger flowers (Kaczperski et al., 1991). In addition, an elevated DLI inhibited stem and peduncle extension growth in pansy (Viola xwittrockiana Gams.) (Niu et al., 2000).

Increasing DLI can promote the growth rate of herbaceous ornamentals by increasing photosynthesis (Nemali and van Iersel, 2004). A higher mean DLI increases dry matter and flower bud number at first flowering in rose yarrow (Achillea $\times$ millefolium L.), gaura (Gaura lindheimeri Engelm. \& Gray), lisianthus [Eustoma grandiflorum (Raf.) Shinn], red salvia (Salvia splendens Sell ex Roem. \& Schult.), and French marigold (Tagetes patula L.) (Fausey et al., 2005; Islam et al., 2005; Moccaldi and Runkle, 2007). When the ambient DLI is low, the only way to increase the DLI is to provide SL. However, SL during the entire production period is usually not commercially feasible because significant investments in lighting equipment and operation are required (Graper et al., 1990).

One of the most cost-effective uses of SL is during the production of young plants, when plants are grown at a high density (Graper et al., 1990). Increasing DLI during propagation can increase transplant quality and hasten subsequent flowering in several herbaceous ornamentals. For example, as mean DLI during the seedling stage increased from 4.1 to $14.2 \mathrm{~mol} \cdot \mathrm{m}^{-2} \cdot \mathrm{d}^{-1}$, seedling shoot dry mass per internode (a measure of plant quality) increased linearly by $64 \%, 47 \%$, $64 \%$, and $68 \%$ and flowering occurred 10 , 12, 4, and $12 \mathrm{~d}$ earlier in celosia (Celosia argentea var. plumosa L.), impatiens (Impatiens walleriana Hook.), French marigold, and pansy, respectively (Pramuk and Runkle, 2005 b). Similarly, an increase in propagation DLI, from 1.2 to $7.5 \mathrm{~mol} \cdot \mathrm{m}^{-2} \cdot \mathrm{d}^{-1}$, increased the root and shoot dry mass of petunia 'Tiny Tunia Violet Ice' by $737 \%$ and $106 \%$, respectively (Lopez and Runkle, 2008). In addition, subsequent time to flower decreased from 50 to $29 \mathrm{~d}$ as the propagation mean DLI increased from 1.4 to $10.7 \mathrm{~mol} \cdot \mathrm{m}^{-2} \cdot \mathrm{d}^{-1}$. The objective of this study was to determine the impact of increasing the DLI for different durations and production periods during the seedling stage on transplant quality and subsequent growth and development of petunia and pansy.

\section{Materials and Methods}

Daily light integral treatments during the seedling stage. Seeds of petunia 'Madness Red' and pansy 'Delta Premium Yellow' were 
sown into 288 -cell $(5-\mathrm{mL})$ plug trays at a commercial greenhouse (Raker's Acres, Inc., Litchfield, MI) and then moved to glassglazed greenhouses at Michigan State University (MSU) within $1 \mathrm{~d}$. Trays were cut in half (for two blocks) and randomly placed under a 16-h photoperiod provided by sunlight plus direct $\left(\mathrm{SL} ; 90 \mu \mathrm{mol} \cdot \mathrm{m}^{-2} \cdot \mathrm{s}^{-1}\right)$ or diffuse lighting [photoperiodic lighting (PL); $3 \mu \mathrm{mol} \cdot \mathrm{m}^{-2} \cdot \mathrm{s}^{-1}$ ] from high-pressure sodium (HPS) lamps. Lamps were operated when the ambient greenhouse photosynthetic photon flux (PPF) was less than $400 \mu \mathrm{mol} \cdot \mathrm{m}^{-2} \cdot \mathrm{s}^{-1}$ from 0600 to $2200 \mathrm{HR}$.

The seedling stage duration was divided into equal thirds: $9 \mathrm{~d}$ for petunia and $11 \mathrm{~d}$ for pansy. Plants either remained under SL or PL during the entire seedling stage or were exposed to SL for one-third or two-thirds of the duration for a total of seven lighting treatments: LLL, HLL, LHL, LLH, HHL, $\mathrm{LHH}$, and $\mathrm{HHH}$, in which each $\mathrm{L}=$ low (PL) and $\mathrm{H}=$ high (SL) for 9 or $11 \mathrm{~d}$. For example, pansy plugs that received the HLL treatment were provided with SL during the first 11 $\mathrm{d}$ and PL during the last $22 \mathrm{~d}$. Soon after seedling emergence, plugs were thinned to one seedling per cell. Seedlings were watered with reverse-osmosis water containing a water-soluble fertilizer to provide the following $\left(\mathrm{mg} \cdot \mathrm{L}^{-1}\right)$ : 62.5 nitrogen $(\mathrm{N}), 6.5$ phosphorus $(\mathrm{P}), 62.5$ potassium $(\mathrm{K}), 55$ calcium (Ca), 17 magnesium $(\mathrm{Mg}), 14.5$ sulfur $(\mathrm{S})$, 0.5 iron (Fe), 0.05 boron (B) and molybdenum (Mo), and 0.25 manganese $(\mathrm{Mn})$, zinc $(\mathrm{Zn})$, and copper $(\mathrm{Cu})$ (MSU Special; Greencare Fertilizers, Chicago, IL). At the end of the seedling stage, eight of the 144 seedlings in each block were randomly selected (without use of border plants) and plant height, leaf number, and shoot dry mass were recorded. This experiment was performed twice beginning on 22 Jan. (Season I) and 19 Mar. (Season II). In Season II, 15\% and 30\% shadecloth was used during the seedling stage so that the ambient mean DLI was similar to that in Season I.

Common environment during the finish stage. At the end of the seedling stage, eight additional seedlings randomly selected (without use of border plants) from each block were transplanted into $10-\mathrm{cm}$ pots containing a $70 \%$ peatmoss, $21 \%$ perlite, and $9 \%$ vermiculite potting media (SUREMIX; Michigan Grower Products, Inc., Galesburg, MI). Pots were randomly placed on benches with SL and a 16-h photoperiod (as described previously) in a greenhouse maintained at $20{ }^{\circ} \mathrm{C}$. In Season II, $\approx 30 \%$ whitewash was substituted for $15 \%$ shadecloth used during the seedling stage so that light conditions were similar to that in Season I. Plants were top-irrigated with a water-soluble fertilizer (as described previously) to provide the following $\left(\mathrm{mg} \cdot \mathrm{L}^{-1}\right): 125 \mathrm{~N}, 13 \mathrm{P}, 125 \mathrm{~K}$, $110 \mathrm{Ca}, 34 \mathrm{Mg}, 29 \mathrm{~S}, 1 \mathrm{Fe}, 0.1 \mathrm{~B}$ and $\mathrm{Mo}$, and $0.5 \mathrm{Mn}, \mathrm{Zn}$, and $\mathrm{Cu}$. Data collected on finished plants include date of visible bud (VB) and first flowering, flower bud and node number at first flowering, plant height, and shoot dry mass at first flowering.
Environmental monitoring and data analysis. In all environments, air temperature was measured by aspirated and shielded thermocouples, plug medium temperature was mea- sured by placing thermocouples just below the media surface, and light intensity was measured with line quantum sensors (Apogee Instruments, Inc., Logan, UT) positioned on

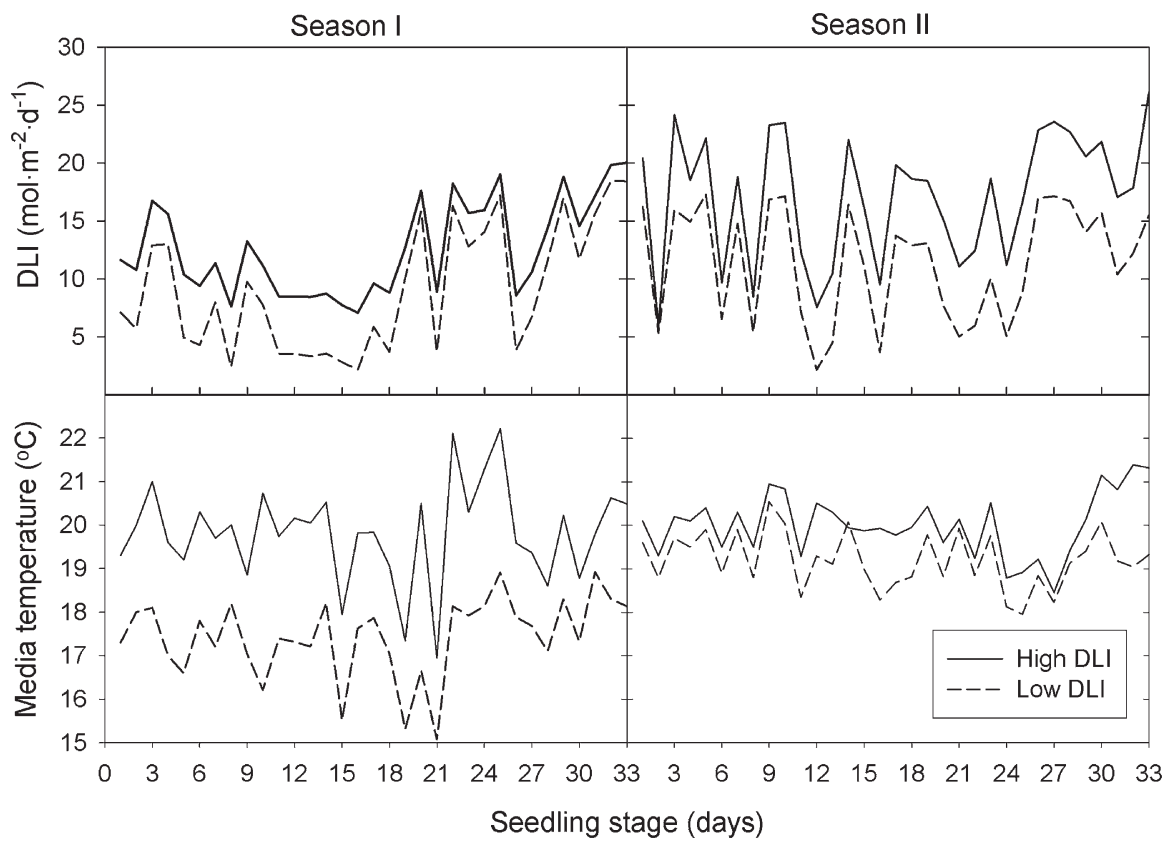

Fig. 1. Actual daily light integral (DLI) and plug media temperature during seedling development. Plugs of petunia and pansy were placed under supplemental (at $\left.90 \mu \mathrm{mol} \cdot \mathrm{m}^{-2} \cdot \mathrm{s}^{-1}\right)$ or photoperiodic (3 $\mu \mathrm{mol} \cdot \mathrm{m}^{-2} \cdot \mathrm{s}^{-1}$ ) lighting from high-pressure sodium lamps to achieve the high or low DLI treatments, respectively. Seedlings were grown for 27 or $33 \mathrm{~d}$ and received supplemental lighting for one-third, two-thirds, the entire duration, or no part of the seedling stage.

Table 1. Mean daily light integral (DLI) and media and air temperature during three seedling stage periods of equal durations and the finish stages as measured by line quantum sensors at plant height and thermocouples.

\begin{tabular}{|c|c|c|c|c|c|c|c|c|c|}
\hline \multirow[b]{3}{*}{ Season } & \multirow[b]{3}{*}{ Lighting } & \multicolumn{5}{|c|}{$\operatorname{DLI}\left(\mathrm{mol} \cdot \mathrm{m}^{-2} \cdot \mathrm{d}^{-1}\right)$} & \multicolumn{3}{|c|}{ Temperature $\left({ }^{\circ} \mathrm{C}\right)$} \\
\hline & & \multicolumn{4}{|c|}{ Seedling stage period } & \multirow[b]{2}{*}{ Finish stage } & \multicolumn{2}{|c|}{ Seedling stage } & \multirow[b]{2}{*}{ Finish stage (air) } \\
\hline & & 1 & 2 & 3 & $\overline{\text { Mean }}$ & & Media & Air & \\
\hline \multicolumn{10}{|c|}{ Petunia 'Madness Red' } \\
\hline \multirow[t]{2}{*}{ I } & PL & 7.6 & 4.1 & 11.2 & 7.6 & 15.1 & 17.2 & 20.5 & 21.0 \\
\hline & SL & 11.8 & 8.8 & 14.1 & 11.6 & & 19.6 & 20.7 & \\
\hline \multirow[t]{3}{*}{ II } & PL & 12.6 & 9.9 & 10.0 & 10.8 & 19.7 & 19.5 & 21.2 & 20.8 \\
\hline & SL & 16.8 & 15.5 & 16.7 & 16.3 & & 20.1 & 21.0 & \\
\hline & \multicolumn{9}{|c|}{ Pansy 'Delta Premium Yellow' } \\
\hline \multirow[t]{2}{*}{ I } & PL & 6.9 & 6.9 & 13.4 & 9.0 & 15.2 & 17.3 & 20.6 & 21.0 \\
\hline & SL & 11.2 & 10.9 & 15.9 & 12.6 & & 19.9 & 20.8 & \\
\hline \multirow[t]{2}{*}{ II } & PL & 12.5 & 8.8 & 13.0 & 11.4 & 17.6 & 19.3 & 21.2 & 20.3 \\
\hline & SL & 17.0 & 14.7 & 19.9 & 17.2 & & 20.2 & 21.1 & \\
\hline
\end{tabular}

PL and $\mathrm{SL}=$ photoperiodic (at $3 \mu \mathrm{mol} \cdot \mathrm{m}^{-2} \cdot \mathrm{s}^{-1}$ ) and supplemental (at $90 \mu \mathrm{mol} \cdot \mathrm{m}^{-2} \cdot \mathrm{s}^{-1}$ ) lighting from highpressure sodium lamps, respectively.

Table 2. Significance of season (S), lighting treatment (LT), and their interaction $(\mathrm{S} \times \mathrm{LT})$ on the characteristics of transplant growth, flowering, and plant quality.

\begin{tabular}{|c|c|c|c|c|c|c|c|}
\hline \multirow[b]{2}{*}{ Source } & \multirow[b]{2}{*}{$\mathrm{df}$} & \multicolumn{2}{|c|}{ At transplant } & \multicolumn{2}{|c|}{ Days to } & \multicolumn{2}{|c|}{ At first flowering } \\
\hline & & Leaf number & $\overline{\text { Dry mass }}$ & Visible bud & First flower & Flower bud no. & Dry mass \\
\hline \multicolumn{8}{|c|}{ Petunia 'Madness Red' } \\
\hline $\mathrm{S}$ & 1 & $* * *$ & $* * *$ & $* * *$ & *** & $* * *$ & $* * *$ \\
\hline LT & 6 & *** & $* * *$ & $* * *$ & *** & *** & $* * *$ \\
\hline $\mathrm{S} \times \mathrm{LT}$ & 6 & $* * *$ & $* * *$ & $* *$ & $* * *$ & $* * *$ & $* * *$ \\
\hline \multicolumn{8}{|c|}{ Pansy 'Delta Premium Yellow' } \\
\hline $\mathrm{S}$ & 1 & $* * *$ & $* * *$ & $* * *$ & $* * *$ & NS & NS \\
\hline LT & 6 & $* * *$ & $* * *$ & $* * *$ & $* * *$ & *** & $* * *$ \\
\hline$\underline{\mathrm{S} \times \mathrm{LT}}$ & 6 & NS & NS & NS & NS & NS & NS \\
\hline
\end{tabular}

NS, **, ***Nonsignificant or significant at $P<0.01$ or $P<0.001$, respectively. 


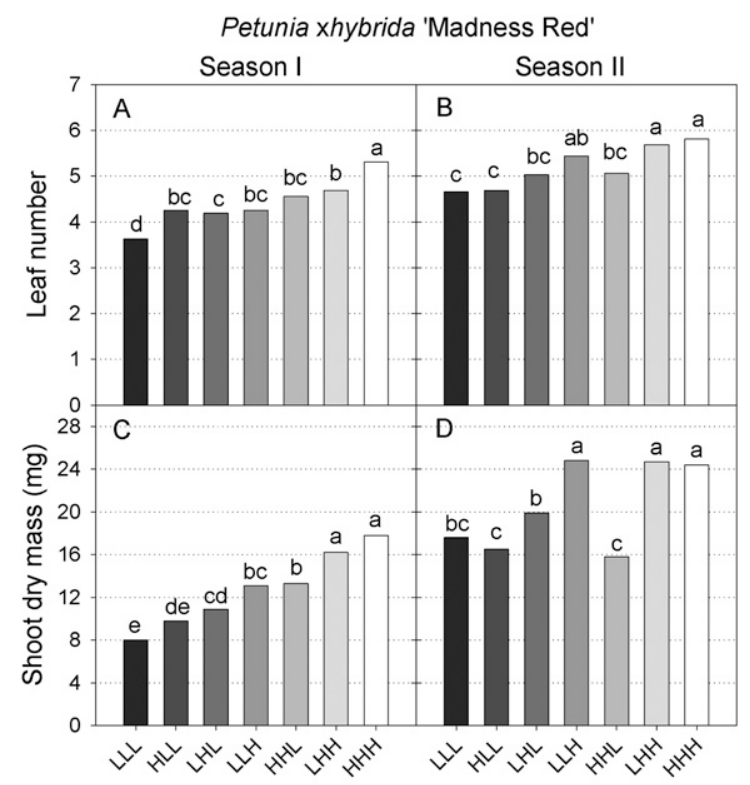

Lighting treatments

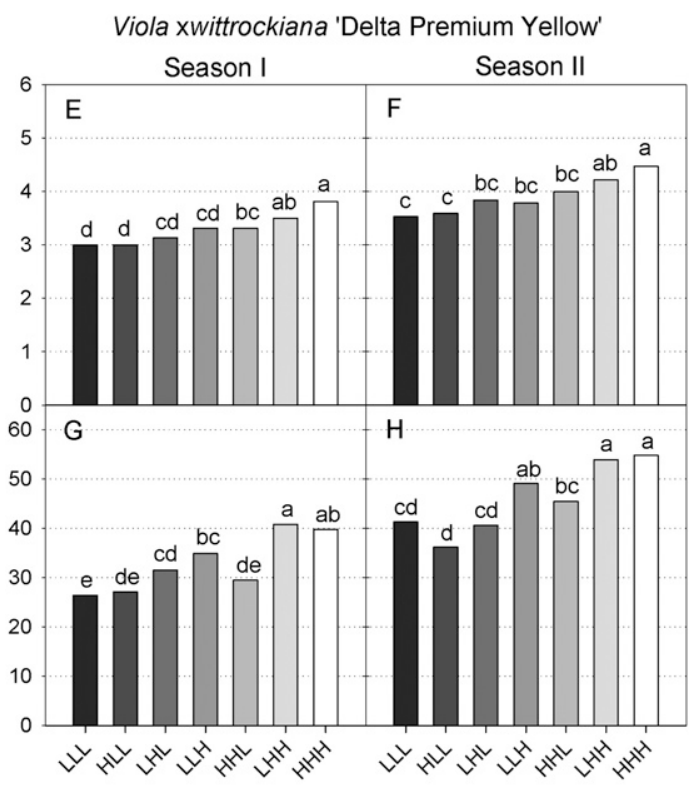

Lighting treatments

Fig. 2. Leaf number and shoot dry mass at transplant as influenced by photoperiodic lighting [low (L)] or supplemental lighting [high (H)] during the seedling stage. The 27- and 33-d seedling stage for petunia and pansy, respectively, was divided into equal thirds with each letter (L or H) representing the lighting treatment during that period. Within-graph means followed by the same letter are not significantly different by Tukey's honestly significant difference test at $P \leq 0.05$.

benches at plant height. Sensors were connected to data loggers (CR10; Campbell Scientific, Logan, UT) that collected data every $10 \mathrm{~s}$ and recorded hourly means. Actual mean DLI, plug media temperature, and air temperature were calculated during the seedling and finishing stages (Fig. 1; Table 1).

The experiment was repeated in time with two blocks each consisting of one-half of a plug tray per species and replicate. Blocks were randomly positioned within the experimental treatments. Plant data were analyzed using SAS (SAS Institute, Inc., Cary, NC) mixed model procedure (PROC MIXED) for analysis of variance and regression analysis was performed in SigmaPlot 10.0 (SPSS, Chicago, IL).

\section{Results}

Environmental conditions during the experiment. The DLIs varied by day, between treatments, and between seasons, although the SL treatment continuously provided seedlings with more light than the PL treatment did (Fig. 1). In Season I, the mean DLI under SL was 4.0 and $3.6 \mathrm{~mol} \cdot \mathrm{m}^{-2} \cdot \mathrm{d}^{-1}$ higher than under PL for petunia and pansy, respectively; in Season II, the mean DLI was 5.5 and 5.8 $\mathrm{mol} \cdot \mathrm{m}^{-2} \cdot \mathrm{d}^{-1}$ greater, respectively, than under PL (Table 1). The mean DLI in Season II was higher than that of Season I during both the seedling and finish stages. Plug medium temperature under PL in Season I was a mean of $2.5{ }^{\circ} \mathrm{C}$ lower than under SL, whereas the medium temperatures under PL and SL were within $0.9{ }^{\circ} \mathrm{C}$ in Season II. In Season I, seedling emergence of petunia and pansy was hastened by $\approx 1 \mathrm{~d}$ under SL (data not
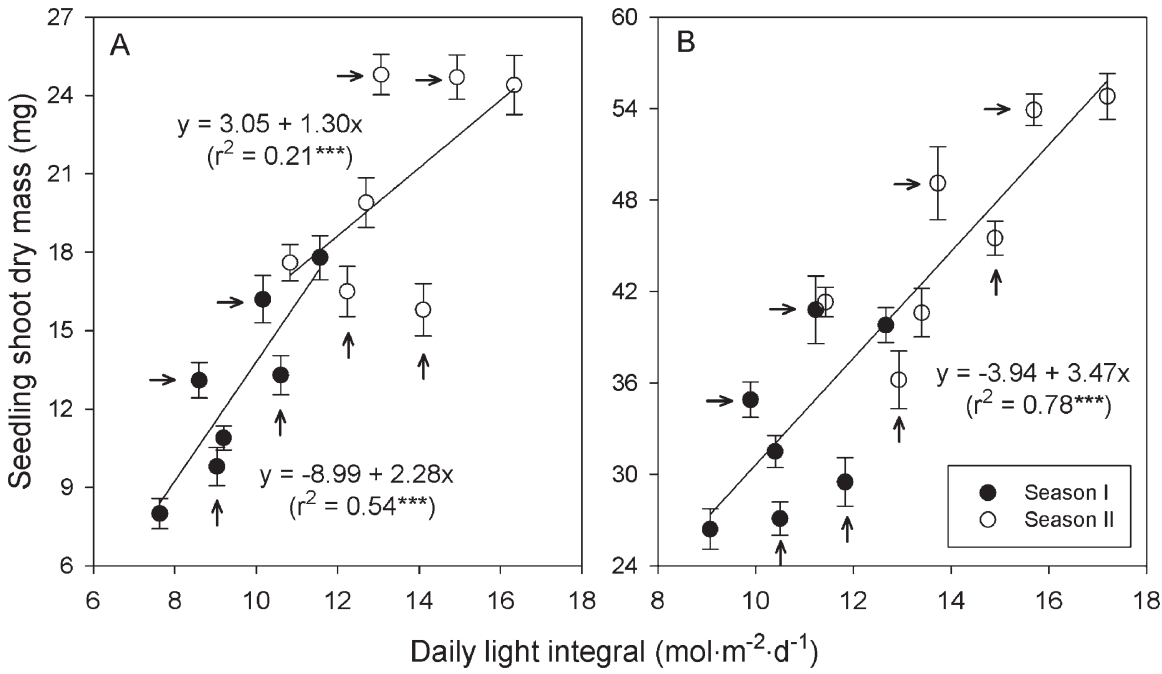

Fig. 3. Relationship between mean daily light integral and shoot dry mass of seedlings in petunia (A) and pansy (B) during Seasons I and II. Horizontal arrows represent supplemental lighting during the last one-third or two-thirds of the seedling stage and vertical arrows represent supplemental lighting during the first third or two-thirds of the seedling stage. Treatment means are provided but regression analysis was performed with all data. Bars represent SE.

shown), which can be attributed to the higher media temperature. Air temperatures were generally similar among treatments during the seedling and finish stages.

Seedling growth. SL during the seedling stage promoted leaf development and dry mass accumulation of transplants in petunia and pansy (Table 2; Fig. 2). Leaf number at transplant generally increased as exposure to SL duration increased in both species. However, SL provided only during the first, second, or third period (HLL, LHL, and LLH, respectively) did not increase leaf number of pansy. In petunia, one period of
SL increased leaf number regardless of timing in Season I but only when delivered during the third period in Season II. Two periods of SL (HHL or LHH) had similar effects on leaf number, except for Season II in petunia, in which plants provided with SL during the last two periods had more leaves than plants provided with SL during the first two periods. Seedlings lighted the entire time $(\mathrm{HHH})$ had a leaf count similar to that under the LHH, but not HHL, in pansy and during Season II of petunia.

Shoot dry mass of seedlings at transplant showed trends somewhat similar to those of 
leaf number. When seedlings were provided with the same duration of high light, SL promoted dry matter accumulation more during the latter period than the early period of the seedling stage (Fig. 2). In all instances, seedlings provided with SL during the second and third periods had a mass similar to that of seedlings provided with continuous SL, and both were greater than that of seedlings under the HHL treatment.

Shoot dry mass linearly increased with increasing DLI during the seedling stage both in petunia (Fig. 3A) and pansy (Fig. 3B). Seedlings in Season II had a greater mass than those in Season I because the former received a higher mean DLI. SL during the latter seedling stages (LLH or LHH; vertical arrows) promoted dry matter accumulation more than that during the earlier stage (HLL or HHL; horizontal arrows). Observations of the root systems indicated that seedlings of both crops developed much greater root systems as exposure to SL increased, although data were not collected to substantiate this assessment.

Flowering. SL during the seedling stage hastened flowering in petunia and pansy when delivered during the second seedling stage, third seedling stage, or both (Fig. 4). SL during the first period had no effect on time to VB irrespective of species and season. Petunia developed VB earlier when provided with SL during the last period (LLH) in both seasons, and pansy in Season I, compared with plants continuously under PL. In both species and seasons, plants under the $\mathrm{LHH}$ and $\mathrm{HHH}$ reached $\mathrm{VB}$ at the same time, which was 3 to $4 \mathrm{~d}$ earlier than plants under the LLL treatment. With the exception of petunia in Season I, seedlings that received SL during the first two periods (HHL) subsequently reached VB at the same time as seedlings under the LLL treatment. Days to first flower showed trends very similar to those of days to VB in both species and in both seasons.

Finish plant quality. Plant quality at first flowering, measured by flower number and shoot dry mass, was sometimes lower in petunia and pansy when plants received SL during the seedling stage (Fig. 4). In petunia, flower count and dry mass were generally lower for seedlings that received SL during the last period than for seedlings that did not. In Season I, most plants that received SL during the seedling stage had fewer flower buds and less plant mass than those that did not, but similar trends were not observed in Season II. The number of flower buds in Season II was lower than that in Season I in petunia, whereas it was similar between seasons in pansy. Time to first flower was correlated positively with shoot dry mass at first flowering in both species and seasons; the later that flowering occurred, the greater the plant mass (Fig. 5).

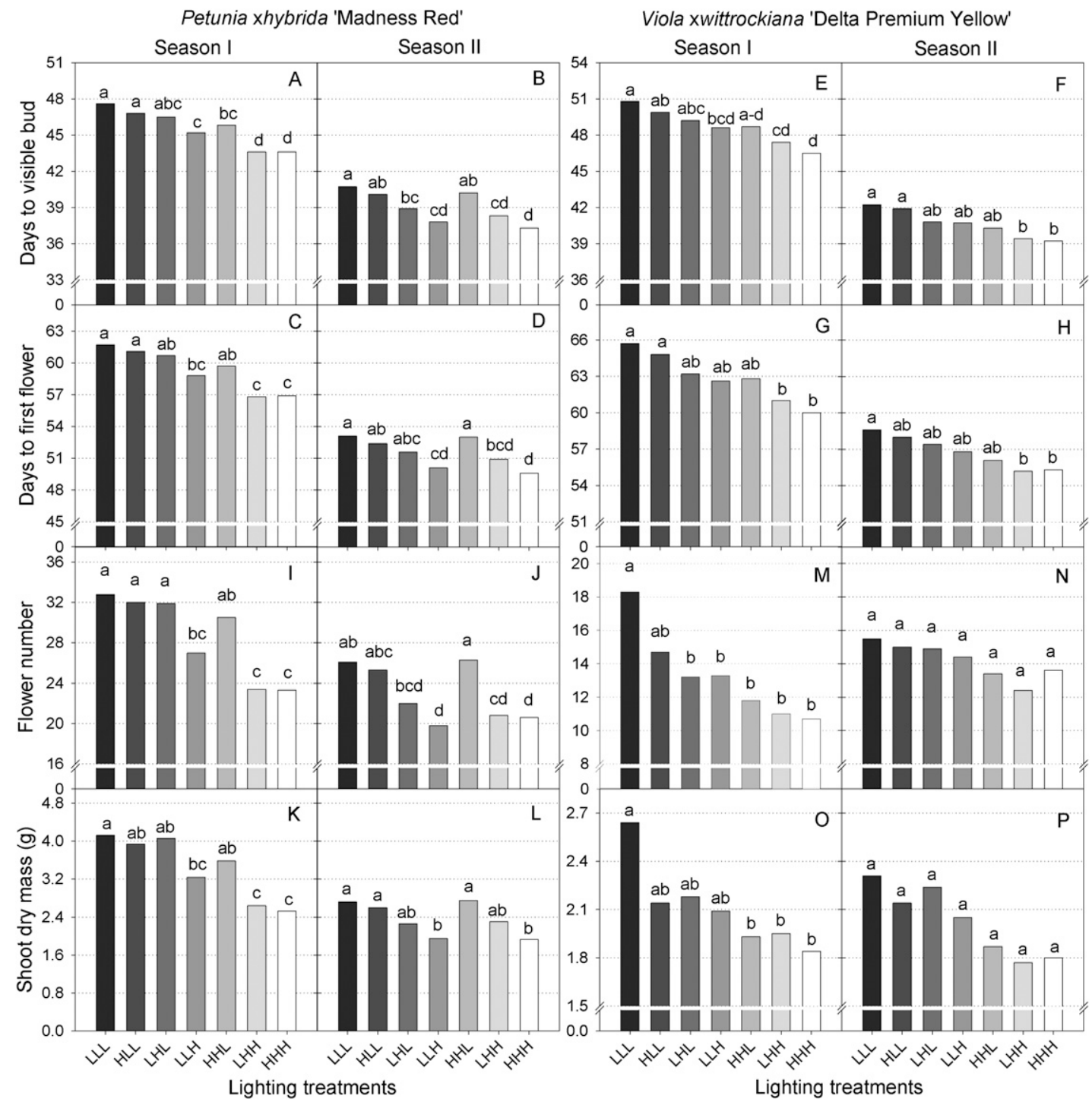

Fig. 4. Days to visible flower bud and first open flower after transplant and flower number and shoot dry mass at first flower as influenced by photoperiodic lighting [low (L)] or supplemental lighting [high $(\mathrm{H})]$ during the seedling stage. The 27- and 33-d seedling stage for petunia and pansy, respectively, was divided into equal thirds with each letter $(\mathrm{L}$ or $\mathrm{H})$ representing the lighting treatment during that period. Within-graph means followed by the same letter are not significantly different by Tukey's honestly significant difference test at $P \leq 0.05$. 


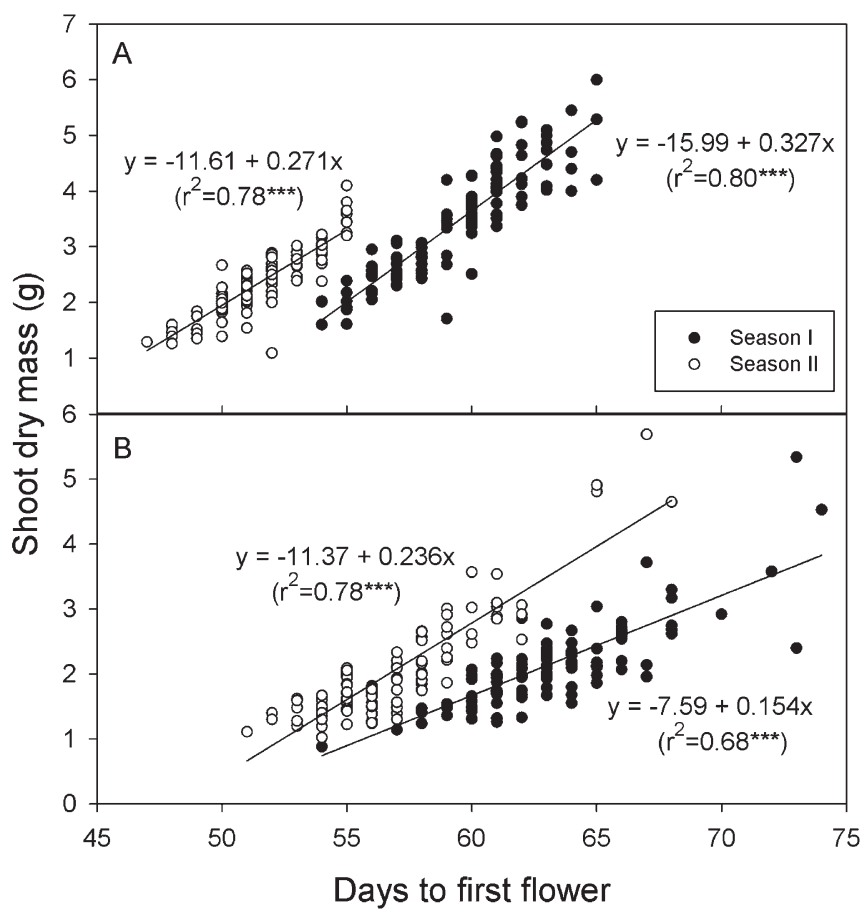

Fig. 5. Relationship between days to flower and shoot dry mass at first flowering in petunia (A) and pansy (B).

\section{Discussion}

Attributes of high-quality transplants typically include a high shoot dry mass, a welldeveloped root system, and minimal internode elongation. These characteristics help ensure survival during shipping and the transition to the finish production environment (Lopez and Runkle, 2008; Pramuk and Runkle, 2005b). Plug-grown wax begonia (Begonia semperflorens-cultorum Hort. 'Pizzazz Red' and 'Vodka') reached transplantable dry mass (i.e., $3 \mathrm{mg}$ ) and leaf area (i.e., $1.4 \mathrm{~cm}^{2}$ ) after 4 weeks of metal halide SL at $125 \mu \mathrm{mol} \cdot \mathrm{m}^{-2} \cdot \mathrm{s}^{-1}$ (6 weeks after seeding), whereas SL at 50 $\mu \mathrm{mol} \cdot \mathrm{m}^{-2} \cdot \mathrm{s}^{-1}$ and the control required an additional 2 and 4 weeks, respectively (Kessler et al., 1991). In this study, increasing DLI during the seedling stage promoted seedling dry matter accumulation (Fig. 3) and root development (data not shown) both in petunia and pansy.

The effect of increasing DLI on transplant growth varied depending on timing and duration during the seedling stage (Fig. 2). When plants were treated with high DLI for only one-third of the seedling stage, SL during the last third (LLH) was most effective. Increasing DLI for the latter two-thirds was more effective than for the last third alone and was similar to providing SL for the entire seedling stage, whereas SL for the first third did not influence the growth and development of the seedlings and finish plants compared with the control treatment (PL for the entire seedling stage). In this study, the emergence and unfolding of cotyledons occurred during the first third period; one to three and one to two true leaves in petunia and pansy, respectively, were unfolded during the second third; and four to six and three to four true leaves in petunia and pansy, respectively, were unfolded during the last third of the seedling stage. Therefore, there was very little leaf area to receive the SL during the first third period and hence, it was generally not effective. Graper et al. (1990) reported that the critical period for the irradiation of petunia seedlings was 10 to 15 or 10 to $20 \mathrm{~d}$ after germination, and HPS SL at $83 \mu \mathrm{mol} \cdot \mathrm{m}^{-2} \cdot \mathrm{s}^{-1}$ before first leaf expansion was often $30 \%$ less effective. The last third period of petunia in our study was $\approx 12$ to 21 $\mathrm{d}$ after germination because germination occurred at 5 to $7 \mathrm{~d}$ after seeding.

The effect of supplemental HPS lighting for seedlings is affected by ambient light conditions. Graper et al. (1990) reported that the efficacy of SL decreased as ambient DLI increased from January to April. In this study, the mean DLI provided to the seedlings of Season II was much higher than that of Season I (Table 1; Fig. 1) and the differences in seedling growth and subsequent growth and development between treatments decreased in Season II, although the difference in DLI between the control and SL was greater in Season II than Season I. Therefore, we conclude that SL after March, when the mean DLI is greater than $10 \mathrm{~mol} \cdot \mathrm{m}^{-2} \cdot \mathrm{d}^{-1}$, is less effective.

Increasing DLI during the seedling stage promoted leaf unfolding as well as dry matter accumulation. Developmental rates, including leaf unfolding, are influenced by temperature. SL increased root zone and leaf temperature (Graper and Healy, 1991) and shoot-tip temperature of plants (Faust and Heins, 1997). In Season I of this study, HPS lighting at $90 \mu \mathrm{mol} \cdot \mathrm{m}^{-2} \cdot \mathrm{s}^{-1}$ increased media temperature by $2.4^{\circ} \mathrm{C}$, which may partially explain the acceleration of germination by $\approx 1 \mathrm{~d}$ (data not shown). In addition, SL for the latter period may partially promote leaf unfolding by increasing shoot-tip temperature (not measured). Faust and Heins (1997) reported that Catharanthus roseus exposed to supplemental light from HPS lamps at 50, 75, and $100 \mu \mathrm{mol} \cdot \mathrm{m}^{-2} \cdot \mathrm{s}^{-1}$ were $1.2,1.5$, and 1.7 ${ }^{\circ} \mathrm{C}$ warmer, respectively, than plants in darkness. HPS SL for $24 \mathrm{~h}$ at $160 \mu \mathrm{mol} \cdot \mathrm{m}^{-2} \cdot \mathrm{s}^{-1}$ increased media and plant temperature by 3.6 and $4.3{ }^{\circ} \mathrm{C}$, respectively, and the fresh weight of petunia seedlings by $88 \%$ at $12 \mathrm{~d}$ after treatment (Graper and Healy, 1991). Elevating media and plant temperature $(+3.6$ and $+4.8^{\circ} \mathrm{C}$, respectively) without increasing the $P P F$ by using infrared (IR) lamps increased fresh weight by $38 \%$, and HPS lighting removing IR radiation increased fresh weight by $68 \%$, elevating media and leaf temperature by 2.0 and $2.5^{\circ} \mathrm{C}$, respectively. Therefore, improvement of seedling growth by SL is the result of increases in both photosynthetic photons received by leaves and plant temperature.

Increasing DLI during the seedling stage decreased the time to VB and first flowering both in petunia and pansy, and such effect was greater as SL was provided during a longer duration and/or at a latter stage (Fig. 4). In Season I, increasing DLI during the entire seedling stage $(\mathrm{HHH})$ and during the latter two-thirds $(\mathrm{LHH})$ reduced the time to first flowering by 4.8 and $4.7 \mathrm{~d}$ in petunia and 4.7 and $5.7 \mathrm{~d}$ in pansy, respectively, compared with that in the control (LLL). Pramuk and Runkle (2005b) reported that flowering of Celosia, Impatiens, Saliva, Tagetes, and Viola occurred 10, 12, 11, 4, and 12 d earlier, respectively, as mean DLI during the seedling stage increased from 4.1 to 14.2 $\mathrm{mol} \cdot \mathrm{m}^{-2} \cdot \mathrm{d}^{-1}$. Petunia provided with HPS SL at $83 \mu \mathrm{mol} \cdot \mathrm{m}^{-2} \cdot \mathrm{s}^{-1}$ at longer and/or later periods during the seedling stage of 0 to 20 $\mathrm{d}$ after germination flowered earlier (Graper et al., 1990). However, the effect of high DLI on flowering was smaller in Season II of this study and insignificant in spring because of higher ambient irradiance.

In petunia 'Madness Red', the HHH treatment decreased the node number below the first open flower by 0.8 and 0.7 nodes in Seasons I and II, respectively, compared with LLL (12.3 and 11.8 nodes) (data not shown). The HHH treatment decreased the node number below the first open flower of pansy 'Delta Premium Yellow' by 1.0 node compared with LLL (6.6 nodes) in Season I (data not shown). Erwin et al. (2004) described that plants have a facultative irradiance (FI) response when they develop fewer nodes before flower initiation from an increase in DLI. Although the DLI ranges were narrow and duration of treatments was short, petunia and pansy showed the characteristics of FI response. Erwin et al. (2004) reported that pansy 'Delta Pure White' under DLI treatment from transplant to flowering had a FI response, whereas Pramuk and Runkle (2005b) did not find a FI response from pansy 'Crystal Bowl Yellow' under DLI treatment only during the seedling 
stage (i.e., for 26 d). 'Delta Premium Yellow' under a similar period (i.e., $33 \mathrm{~d}$ ) but narrower DLI range (i.e., 7.6 to $11.6 \mathrm{~mol} \cdot \mathrm{m}^{-2} \cdot \mathrm{d}^{-1}$ ) in this study was thought to be more FI-responsive than 'Crystal Bowl Yellow', which was unaffected by increasing DLI from 4.1 to 14.2 $\mathrm{mol} \cdot \mathrm{m}^{-2} \cdot \mathrm{d}^{-1}$.

Adams et al. (1999) reported that the photoperiod-insensitive juvenile phase decreased from $36 \mathrm{~d}$ to $23 \mathrm{~d}$ with increasing total solar radiation from 1.6 to 2.6 $\mathrm{MJ} \cdot \mathrm{m}^{-2} \cdot \mathrm{d}^{-1}$ in 'Express Blush Pink' petunia. The length of the juvenile phase may be under direct genetic control or it may be linked to plant size, assimilate availability, distance of the apex from the root, and apex size, which are influenced by temperature and light integral (Adams et al., 1999). SL during the latter seedling stage decreased the juvenile phase more than SL before or immediately after germination. In wax begonia, metal halide SL $\left(125 \mu \mathrm{mol} \cdot \mathrm{m}^{-2} \cdot \mathrm{s}^{-1}\right.$ for 16 $\mathrm{h} \cdot \mathrm{d}^{-1}$ ) for 2 weeks from the first true leaf stage decreased days to flowering and number of nodes (Kessler et al., 1991). Plant quality at first flowering, measured by flower number and shoot dry mass, decreased as days to first flower decreased (Fig. 5), which might be attributed to a shorter juvenile phase for vegetative growth.

The results of this study showed that SL during the seedling stage improved transplant quality and hastened subsequent flowering. Its promoting effects were greater at the latter stages of seedling growth. However, SL for plugs reduced plant quality at first flowering. Therefore, greenhouse growers could choose the time and period of the SL for plugs of bedding plants depending on final container size. In addition, the high-light effect might be different, depending on species and cultivar, because it was greater in petunia than pansy in this study, especially in subsequent flowering and plant quality. These results indicate that greenhouse growers could use SL from the two true leaf stage onward to obtain good-quality transplants, rapid flowering, and energy savings when the ambient mean DLI is low (e.g., less than 8 to 10 $\left.\mathrm{mol} \cdot \mathrm{m}^{-2} \cdot \mathrm{d}^{-1}\right)$. Research is needed to apply SL during the latter seedling stages to various bedding plants and to categorize them into several types by their response for practical use in greenhouse production.

\section{Literature Cited}

Adams, S.R., S. Pearson, P. Hadley, and W.M Patefield. 1999. The effects of temperature and light integral on the phases of photoperiod sensitivity in Petunia Xhybrida. Ann. Bot. (Lond.) 83:263-269.

Ball, V. 1998. Bedding plants: Trends and seed basics, p. 201-234. In: Ball, V. (ed.). Ball redbook. 16th Ed. Ball Publishing, Batavia, IL.

Erwin, J., N. Mattson, and R. Warner. 2004. Light effects on annual bedding plants, p. 62-71. In: Fisher, P. and E. Runkle (eds.). Lighting up profits. Meister Media Worldwide, Willoughby, $\mathrm{OH}$.

Fausey, B.A., R.D. Heins, and A.C. Cameron 2005. Daily light integral affects flowering and quality of greenhouse-grown Achillea, Gaura, and Lavandula. HortScience 40:114118.

Faust, J.E. and R.D. Heins. 1997. Quantifying the influence of high-pressure sodium lighting on shoot-tip temperature. Acta Hort. 418:85-91.

Faust, J.E., V. Holcombe, N.G. Rajapakse, and D.R. Layne. 2005. The effect of daily light integral on bedding plant growth and flowering. HortScience 41:114-119.

Graper, D.F. and W. Healy. 1991. High pressure sodium irradiation and infrared radiation accelerate Petunia seedling growth. J. Amer. Soc. Hort. Sci. 116:435-438.

Graper, D.F., W. Healy, and D. Lang. 1990. Supplemental irradiance control of petunia seedling growth at specific stages of development. Acta Hort. 272:153-157.

Islam, N., G.G. Patil, and H.R. Gislerød. 2005. Effect of photoperiod and light integral on flowering and growth of Eustoma grandiflorum (Raf.). Shinn. Sci. Hort. 103:441-451.

Kaczperski, M.P., W.H. Carlson, and M.G. Karlsson. 1991. Growth and development of Petunia $\times$ hybrida as a function of temperature and irradiance. J. Amer. Soc. Hort. Sci. 116:232237.

Kessler, R., A.M. Armitage, and D.S. Koranski. 1991. Acceleration of Begonia semperflorenscultorum growth using supplemental irradiance. HortScience 26:258-260.
Korczynski, P.C., J. Logan, and J.E. Faust. 2002. Mapping monthly distribution of daily light integrals across the contiguous United States. HortTechnology 12:12-16.

Lopez, R.G. and E.S. Runkle. 2008. Photosynthetic daily light integral during propagation influences rooting and growth of cuttings and subsequent development of New Guinea impatiens and petunia. HortScience 43:20522059

Moccaldi, L.A. and E.S. Runkle. 2007. Modeling the effects of temperature and photosynthetic daily light integral on growth and flowering of Salvia splendens and Tagetes patula. J. Amer. Soc. Hort. Sci. 132:283-288.

Nemali, K. and M. van Iersel. 2004. Acclimation of photosynthesis and growth of wax begonias grown at different light levels, p. 22-23. In: Fisher, P.R. and E.S. Runkle (eds.). Lighting up profits. Meister Media Worldwide, Willoughby, $\mathrm{OH}$.

Niu, G., R.D. Heins, A.C. Cameron, and W.H. Carlson. 2000. Day and night temperatures, daily light integral, and $\mathrm{CO}_{2}$ enrichment affect growth and flower development of pansy (Viola ×wittrockiana). J. Amer. Soc. Hort. Sci. 125: 436-441.

Pietsch, G.M., W.H. Carlson, R.D. Heins, and J.E. Faust. 1995. The effect of day and night temperatures and irradiance on development of Catharanthus roseus (L.) 'Grape Cooler'. J. Amer. Soc. Hort. Sci. 120:877-881.

Pramuk, L.A. and E.S. Runkle. 2005a. Modeling growth and development of Celosia and Impatiens in response to temperature and photosynthetic daily light integral. J. Amer. Soc. Hort. Sci. 130:813-818.

Pramuk, L.A. and E.S. Runkle. 2005b. Photosynthetic daily light integral during the seedling stage influences subsequent growth and flowering of Celosia, Impatiens, Salvia, Tagetes, and Viola. HortScience 40:13361339

Runkle, E.S. 2007. Maximizing supplemental lighting. Greenhouse Product News 17:66.

Verberkt, H., R. Heins, and T. Blom. 2004. Supplemental lighting on potted plants, p. 2223. In: Fisher, P.R. and E.S. Runkle (eds.). Lighting up profits. Meister Media Worldwide, Willoughby, $\mathrm{OH}$.

Warrington, I.J. and R.A. Norton. 1991. An evaluation of plant growth and development under various daily quantum integrals. J. Amer. Soc. Hort. Sci. 116:544-551. 